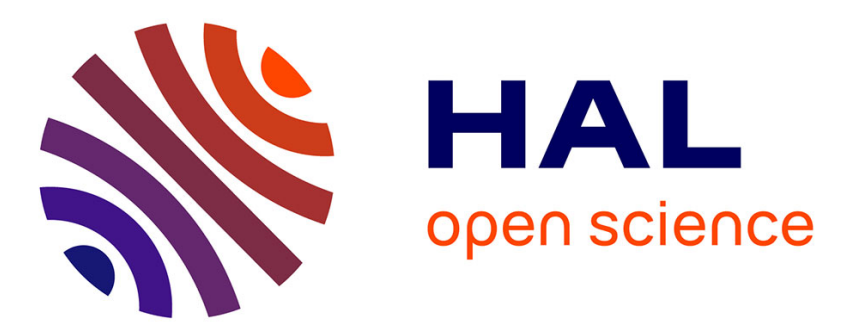

\title{
Designing Digital Climbing Experiences through Understanding Rock Climbing Motivation
}

Richard Byrne, Florian 'floyd' Mueller

\section{To cite this version:}

Richard Byrne, Florian 'floyd' Mueller. Designing Digital Climbing Experiences through Understanding Rock Climbing Motivation. 13th International Conference Entertainment Computing (ICEC), Oct 2014, Sydney, Australia. pp.92-99, 10.1007/978-3-662-45212-7_12 . hal-01408509

\section{HAL Id: hal-01408509 \\ https://hal.inria.fr/hal-01408509}

Submitted on 5 Dec 2016

HAL is a multi-disciplinary open access archive for the deposit and dissemination of scientific research documents, whether they are published or not. The documents may come from teaching and research institutions in France or abroad, or from public or private research centers.
L'archive ouverte pluridisciplinaire HAL, est destinée au dépôt et à la diffusion de documents scientifiques de niveau recherche, publiés ou non, émanant des établissements d'enseignement et de recherche français ou étrangers, des laboratoires publics ou privés. 


\title{
Designing Digital Climbing Experiences through Understanding Rock Climbing Motivation
}

\author{
Richard Byrne and Florian 'Floyd' Mueller \\ Exertion Games Lab, RMIT University, Melbourne, Australia \\ \{rich, floyd\}@exertiongameslab.org \\ http://exertiongameslab.org
}

\begin{abstract}
Interactive systems have been used successfully in sports to assist people in achieving their performance goals, however, we believe that some aspects are often overlooked. In this paper we focus on rock climbing and we examine existing work on climbing from varying fields, including sports science, psychology, and climbing literary works, in order to identify recurring motivational themes. In total we identify and describe five key themes from these works: "risk as a measure of progress", "maintaining challenge", "social engagement", "experiencing beauty and nature", and "documenting and reliving the experience". We then examine how existing digital climbing experiences address these themes and suggest ways in which these interactive climbing designs could embrace the themes they do not yet address. We believe this work will be important not only when designing digital climbing experiences, but also digital experiences for other extreme sports.
\end{abstract}

\section{Introduction}

Using technology to assist with or to encourage improvement in sporting performance is an emerging field of research and development. In recent years jogging, for example, has seen numerous devices or applications aimed at improving the performance of professionals and beginners alike (for example: Nike Plus [19] and Run Keeper [21]). These systems often aim at improving and monitoring an individual's performance by recording their activity and reporting how well they achieved the task. Other sports have also been investigated, such as: cycling [26], swimming [2], rowing [1], and rock climbing [11]. Recent research in rock climbing has focused on interactive climbing designs that provide new ways of interacting with the rock climbing wall. One caveat, we believe, when designing climbing experiences currently is that the technology often takes the focus, with designers asking first 'what can we do with the technology?'. However, we believe that what is overlooked is obtaining an understanding into why rock climbers choose to climb before developing the design. We believe this is an important consideration and something of a missed opportunity since it will allow for the development of digital climbing experiences that cater to climbers' needs and motivations, i.e. supporting the core of the extreme sport experience. 
To address this we survey existing literature related to climbing in order to identify a set of motivational themes we believe could be valuable to consider when designing to support climbing experience. To see how well these themes have been considered we reexamine existing digital climbing experiences and offer our suggestions for design opportunities which could allow these systems to address themes not yet supported.

\section{Identifying Motivational Themes from Climbing Literature}

We know as interaction designers that requirements of the desired user group should be kept in mind throughout the design [20, p.352-388]. However in climbing (and any extreme sport) it is important to consider more than the system requirements since for these groups the experience is just as important (if not more so):

"The whole experience of climbing is important, not one particular part or moment" - Scott Backes [23, p.162]

In this section we investigate existing literature on climbing motivation, including climbing literary works and work from the fields of sport science, psychology and sociology in order to gain an understanding of why climbers climb. By identifying recurring observations and themes present in this work we were able to establish five key motivational themes (which are illustrated in figure 1).

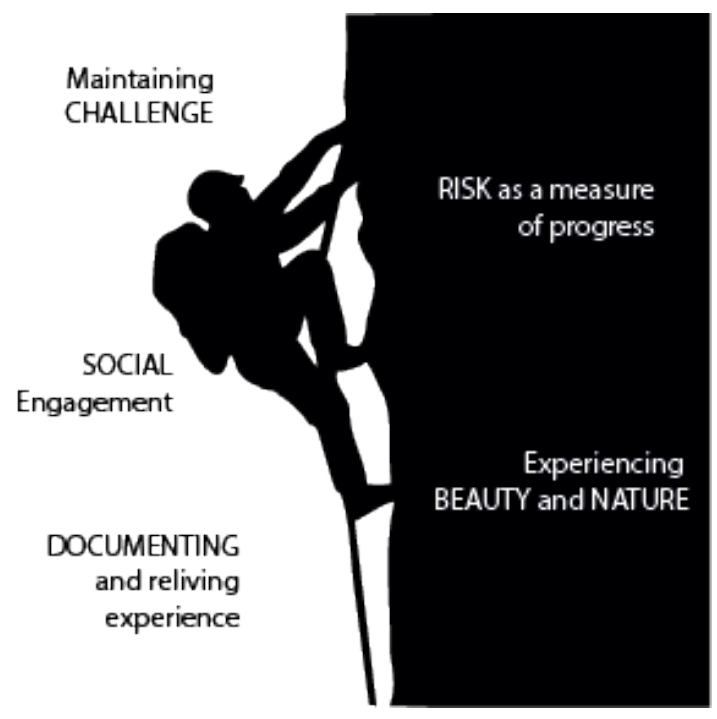

Fig. 1. Motivational themes identified from climbing literature. 


\subsection{Maintaining Challenge}

Levenhagen [15] develops a stage model of climbing purposes describing two primary motivations for climbers: to experience achievement and flow, and to build character. Both these motivations require that challenge is maintained throughout the experience to ensure that a sense of progression is also experienced. This marriage of challenge and flow is also discussed by Csikszentmihalyi et al. [4] who state that an optimal experience of flow can be maintained by "setting ourselves challenges" [5]. Louková and Vomáčko [17] and Vomáčko and Gável [25] also found that "Challenge" was among one of the highest motivations reported by climbers. Therefore we can identify that maintaining challenge is a key theme as it helps to maintain flow and achievement, and to also allow the climber to build character through a sense of achievement.

\subsection{Risk as a Measure of Progress}

Interestingly we initially assumed that extreme sports attract thrill seekers who pursue the sport primarily for the risk involved. However, it appears that risk plays a larger role in climbing as discussed by Ewert [8] who states that climbing simply because of the risk is actually a low motivational factor. This highlights that risk can be a way to measure progress and performance improvement since a climber can evaluate how well they have progressed by climbing a route they previously considered too risky for their skill level. Fave et al. [10] also support this notion as they too explain how risk alone is not a primary motivation factor, but in actuality that it is useful in helping climbers to monitor and track their performance and progression.

\subsection{Social Engagement}

Climbers can be said to experience goals in one of two ways: through extrinsic and intrinsic motivations [17]. Intrinsic goals are those such as completing a new route to prove to climbers that they have progressed (as in the case of risk as a measure of progress), whereas extrinsic goals represent aspects such as social acknowledgement and competition [25]. De Leseleuc et al. [7] even discuss how climbers can be united in a community of belonging. The social aspects of climbing can therefore be said to be split into two categories: on the wall and off the wall. On the wall social engagement can include competition (completing a route a friend does not, doing the route faster, etc.) whereas off the wall can include friendly interactions and climbing discussions. For these reasons we believe that social engagement should be a key theme in climbing motivation.

\subsection{Documenting and Reliving Experience}

Levenhagen [15] comments that due to a sense of flow that exists in climbing it is apparent that climbers can also experience a sense of loss after the climb is completed. Simpson expresses how after his own climbing experience there is a 
"post-coital depression, [a] fleeting saddening loss when it is over" [22, p.116117]. An extreme example of reliving previous experience was undertaken by Conrad Anker [18] who, using equipment relevant to the period, attempted to see if George Mallory (a pioneering climber whose body was found on Mount Everest) would have actually made it to the summit before he died. It is therefore apparent that the desire to relive the experience or document one's climb is another key motivation.

\subsection{Experiencing Beauty and Nature}

Vomáčko and Gável [25] discuss how beauty of mountains is a strong motivational factor which reinforces earlier work detailing how wilderness plays a key factor in adventure pursuits [8, 9]. Additional work has also discussed how mountains are naturally attractive to climbers [24] further enforcing that experiencing beauty and nature is a high motivational factor to climbers.

\section{Motivational Themes Present in Existing Digital Climbing Experiences}

In this section we look at several existing digital climbing experiences which we have grouped according to their shared design properties, i.e. interactive climbing walls, augmented and projection based systems and wearable systems. We identify the themes that are supported by these existing experiences and present design opportunities which theorise how each experience could incorporate the themes they do not currently support. We picked these systems by querying search terms such as "interactive climbing walls" and "climbing experience" on both the ACM Digital Library and Google, and choosing a selection that matched the above groupings.

\subsection{Interactive Climbing Walls}

There has been an interest in creating digital climbing walls solely for the purpose of providing new experiences for climbers. The Digiwall [16], for example, is an interactive climbing wall complete with custom hand and foot holds and an interactive sound system. The holds detect when they are touched and also have the ability to light up and illuminate different routes. Additionally the Digiwall has several games built into it based around these interactive holds such as encouraging the climber to touch the correct hold when it is illuminated. Similarly the Wall-O-Tron [3] makes use of a lighting system to suggest routes or holds that climbers need to interact with.

Themes Addressed These systems encourage a sense of challenge: allowing for different routes to be created, objectives to be achieved and difficulty to be altered depending on climbing ability. They also encourage a sense of rivalry and specifically alter the core climbing experience by turning the wall into a social game experience and thus encouraging social engagement. 
Design Opportunities Though these systems address the themes of maintaining challenge and social engagement there exists the opportunity to embrace the additional themes that we have outlined. For example, reliving the experience could be embraced by recording the pattern of the climb and allowing the climber to "race" their previous attempt by playing it out on the wall in real-time. Risk is removed by the gaming element for more experienced climbers; perhaps the systems could alter routes in real-time based on how well the climber is ascending the wall in order to automatically adapt to their ability. The theme of beauty and nature is absent in this instance as the walls are situated indoors, however, theming the walls or creating a "realistic" rock face could help to create the illusion of being outdoors. Making use of a sound system to create an outdoor ambiance is also a potential approach to help facilitate the outdoor experience and hence beauty and nature.

\subsection{Augmented and Projection-based Systems}

Daiber et al. [6] present the BouldAR system, which uses augmented reality to support collaborative boulder training. The system allows climbers to use their phones to make a virtual bouldering route by overlaying a computer-rendered image of the bouldering wall on the phone screen when the climbers hold their phones in front of the wall. This allows the climbers to click on the screen to outline their chosen route. Furthermore, users are able to track their progress and log successful and unsuccessful bouldering attempts by using a built-in diary. Study results found that participants preferred the smart phone to the paper solution when describing existing routes. This is an interesting finding as the results imply that a digital experience can be adopted by climbing enthusiasts in a positive way. Kajastila et. al. [13] also investigated augmented climbing by tracking the position of a climber and altering projected images on a wall based on their position. For example, climbers are able to move around the wall whilst being chased by a projected chainsaw, with the goal of not getting "hit" and surviving for the maximum amount of time. Additionally suggested climbing routes can be illuminated on the wall as a person climbs - suggesting different paths to take. Those not climbing were also able to participate by suggesting routes on the wall that the current climber should take. This is interesting as it is a system aimed at climbers of differing skills and abilities, which allows the experience to be altered accordingly based on climbers' needs.

Themes Addressed These systems address the themes of social engagement, maintaining challenge, and documenting and reliving the experience. Since it is possible to alter routes and make new ones for the climbers on the fly the theme of Risk as a measure of progress is also addressed.

Design Opportunities Currently these systems work indoors, if they could be extended to work outdoors then this would help embrace the theme of experiencing beauty and nature by making use of a natural, real world environment. 
Routes could perhaps be created by one climber for another that would take what is judged by the route creator as the most scenic. Projection systems could also be configured to simulate outdoor conditions indoors, such as simulating weather conditions, overlaying images of real mountain trails or displaying different scenery for different climbing attempts.

\subsection{Wearable Systems}

The ClimbAX [14] system was designed with climbers that wish to improve their performance in mind. Accelerometers are worn on the climber's wrists which record the climber's movements as they ascend the wall. An automatic assessment is then made on the recorded data in order to report to the climber post-climb information regarding their power, control, stability and speed during the climb. The purpose of the system is to automate and replicate the input climbers would receive from a real life coach. Results from a trial of the system found that the devices were accurate in predicting the score a climber may achieve at competition level. This is interesting since it illustrates how climbing experiences could be utilised by serious climbers who compete at competition level.

Themes Addressed There are several themes addressed by this system, the first is maintaining challenge, which is accomplished since the system reports on the progress of the climber allowing them to ensure they tackle more difficult routes or use new climbing techniques. Documenting and reliving experience is apparent since the progress is recorded and plotted on graphs that can be used in the future to gauge performance. Finally the theme of experiencing beauty and nature could be supported if the system is used outdoors.

Design Opportunities Risk as a measure of progress is affected by such systems since the system is informing the climber that they are improving through data sets and graphs and not through their own judgement. Perhaps a better way to represent progress is to allow the climber to judge their own performance with the system offering suggestions of different routes the climber may want to climb next, e.g. "you did well, why not try something more difficult next time?". The theme of social engagement is limited in this system since a computer is informing the climber of the progress in a bid to replace a human coach. Perhaps such wearable systems could feed information regarding climbers' physiological status to a coach or fellow climbers so that they can help to guide the climber as they ascend a route. Maybe employing additional wearable tools could be a way to do this, for example, using a system like Google Glass [12] to relay audio transmissions to and from the climber. Motivational messages or information from the coach and other climbers could also be shown on the Google Glass display to offer support or suggestions through the climb in an attempt to address the theme of social engagement. 


\section{Conclusion}

In this paper we have highlighted how understanding the motivation of climbers can be used when designing digital climbing experiences. We investigated this in order to address what we believed was a missed opportunity in designing these experiences without first understanding the motivation of climbers. We have presented five motivational themes derived from a review of existing literature including the fields of sports science, psychology, and climbing literary works. Additionally we have examined how these themes have been addressed by climbing experiences and offered design opportunities that can be considered in creating future digital climbing experiences.

This paper represents the initial stages of our investigation into designing digital climbing experiences through understanding climbing motivation and our future work will commence by implementing these themes into prototype systems. Through testing these systems with climbers we hope to examine our themes in order to produce guidelines that can be potentially considered not only when designing digital climbing experiences, but also digital experiences for other extreme sports.

\section{References}

[1] Anderson, R., Harrison, A., Lyons, G.M.: Rowing: Accelerometry-based feedback-can it improve movement consistency and performance in rowing? Sports biomechanics 4(2), 179-195 (2005)

[2] Bächlin, M., Förster, K., Tröster, G.: Swimmaster: a wearable assistant for swimmer. In: Proceedings of the 11th international conference on Ubiquitous computing. pp. 215-224. ACM (2009)

[3] Benchoff, B: Brian Benchoff: Hack A Day Blog - Wall-O-Tron, the interactive rock climbing wall. Available at: http://hackaday.com/2013/06/26/ wall-o-tron-the-interactive-rock-climbing-wall/ [Accessed: 07 April 2014] (2013)

[4] Csikszentmihalyi, M.: Flow: The psychology of optimal experience, vol. 41. HarperPerennial New York (1991)

[5] Csikszentmihalyi, M., Csikszentmihalyi, I.S.: Optimal experience: Psychological studies of flow in consciousness. Cambridge University Press (1992)

[6] Daiber, F., Kosmalla, F., Krüger, A.: BouldAR - Using Augmented Reality to Support Collaborative Boulder Training pp. 1-6 (Feb 2013)

[7] De Leseleuc, E., Gleyse, J., Marcellini, A.: The practice of sport as political expression? rock climbing at claret, france. International sociology 17(1), 73-90 (2002)

[8] Ewert, A.W.: Playing the edge motivation and risk taking in a high-altitude wilderness like environment. Environment and Behavior 26(1), 3-24 (1994)

[9] Ewert, A.W., Hollenhorst, S.J.: Adventure recreation and its implications for wilderness. International Journal of Wilderness 3(2), 21-26 (1997) 
[10] Fave, A.D., Bassi, M., Massimini, F.: Quality of experience and risk perception in high-altitude rock climbing. Journal of Applied Sport Psychology 15(1), 82-98 (2003)

[11] Fuss, F.K., Niegl, G.: Instrumented climbing holds and performance analysis in sport climbing. Sports Technology 1(6), 301-313 (2008)

[12] Google Glass: Available at: http://www.google.com/glass/start/ [Accessed 04 April 2014] (2014)

[13] Kajastila, R., Hämäläinen, P.: Augmented climbing: Interacting with projected graphics on a climbing wall. In: Proceedings of the Extended Abstracts of the 32Nd Annual ACM Conference on Human Factors in Computing Systems. pp. 1279-1284. CHI EA '14, ACM, New York, NY, USA (2014)

[14] Ladha, C., Hammerla, N.Y., Olivier, P., Plötz, T.: ClimbAX. In: the 2013 ACM international joint conference. p. 235. ACM Press, New York, New York, USA (2013)

[15] Levenhagen, M.: A stage model of why climbers climb and how it frames the discussions of recent climbing controversies. Journal of Mountaineering pp. 16-33 (2010)

[16] Liljedahl, M., Lindbergand, S., Berg, J.: Digiwall: an interactive climbing wall. Advances in Computer Entertainment Technology pp. 225-228 (2005)

[17] Louková, T., Vomáčko, L.: motivation for climbing and mountaineering. 4th International Mountain and Outdoor Sports Conference. Outdoor Activities in Educational and Recreational Programmes pp. 135-139 (2008)

[18] MacKenzie, M.: In the Footsteps of Mallory and Irvine: The Wildest Dream. John Murray (2009)

[19] Nike Plus: Available at: https://secure-nikeplus.nike.com/plus/ [Accessed 04 April 2014] (2014)

[20] Rogers, Y., Sharp, H., Preece, J.: Interaction design: beyond humancomputer interaction. John Wiley \& Sons (2011)

[21] Run Keeper: Available at: http://runkeeper.com/ [Accessed 04 April 2014] (2014)

[22] Simpson, J.: The Beckoning Silence. Mountain Books (2003)

[23] Twight, M.: Kiss Or Kill: Confessions of a Serial Climber. The Mountaineers Books (2001)

[24] Vause, M.: Mountaineering: The heroic expression of our age. In: Personal, Societal, and Ecological Values of Wilderness: Sixth World Wilderness Congress. vol. 2, pp. 83-86 (2000)

[25] Vomáčko, L., Gável, L.: Motivation to mountaineering. 5th International Mountain and Outdoor Sports Conference. Outdoor Activities in Educational and Recreational Programmes pp. 122-142 (2010)

[26] Walmink, W., Chatham, A., Mueller, F.: Interaction opportunities around helmet design. In: CHI '14 Extended Abstracts on Human Factors in Computing Systems. pp. 367-370. CHI EA '14, ACM, New York, NY, USA (2014) 